ARTICLE

https://doi.org/10.1038/s41467-019-14211-0

\title{
A simple and versatile nickel platform for the generation of branched high molecular weight polyolefins
}

\author{
Tao Liang ${ }^{1}$, Shabnam B. Goudari ${ }^{1} \&$ Changle Chen (iD) ${ }^{1 \star}$
}

The development of high-performance transition metal catalysts has long been a major driving force in academic and industrial polyolefin research. Late transition metal-based olefin polymerization catalysts possess many unique properties, such as the ability to generate variously branched polyolefins using only ethylene as the feedstock and the capability of incorporating polar functionalized comonomers without protecting agents. Here we report the synthesis and (co)polymerization studies of a simple but extremely versatile $\alpha$-iminoketone nickel system. This type of catalyst is easy to synthesize and modify, and it is thermally stable and highly active during ethylene polymerization without the addition of any cocatalysts. Despite the sterically open nature, these catalysts can generate branched UltraHigh-Molecular-Weight polyethylene and copolymerize ethylene with a series of polar comonomers. The versatility of this platform has been further demonstrated through the synthesis of a dinuclear nickel catalyst and the installation of an anchor for catalyst heterogenization.

\footnotetext{
${ }^{1}$ CAS Key Laboratory of Soft Matter Chemistry, Hefei National Laboratory for Physical Sciences at the Microscale, Department of Polymer Science and Engineering, University of Science and Technology of China, Hefei 230026, China. *email: changle@ustc.edu.cn
} 
F or more than half a century, transition metal-catalyzed olefin polymerization has been a global topic of intense research ${ }^{1-4}$. The metal nickel entered this field as a poison. Ziegler and coworkers demonstrated the famous nickel effect, in which ethylene was converted exclusively to 1-butene using aluminum alkyls in the presence of a small amount of nickel salt ${ }^{5}$. This discovery marks the starting point for the development of the Ziegler catalysts ${ }^{6}$. Since then, the role of nickel has changed drastically after decades of research. Currently, a large number of $\mathrm{Ni}(\mathrm{II})$-based catalysts have been reported with the ability to generate high molecular weight polyolefins. Brookhart's seminal works in 1995 showed that a-diimine nickel catalysts (Fig. 1, I) were capable of producing high molecular weight polyethylene with activities rivaling many early transition metal catalysts ${ }^{7-9}$. The salicylaldimine nickel catalysts (II) developed by Grubbs and co-workers in 2000 represent another notable advance in this field ${ }^{10-14}$. SHOP-type nickel catalysts (III; SHOP $=$ Shell Higher Olefin Process) have been commercialized for the synthesis of linear $\alpha$-olefins ${ }^{15}$. With proper structural modifications, this type of catalyst can produce high molecular weight polyethylene ${ }^{16}$. For example, some nickel complexes bearing $o$-bis(aryl)-phosphinophenolate ligands (IV) possess advantageous properties for ethylene polymerization and copolymerization with acrylate comonomers $^{17,18}$. Recently, extensive research efforts have been focused on the design and development of nickel catalysts based on phosphine-derived ligands $(\mathbf{V}-\mathbf{V I I})^{19-22}$, partially due to their potential for generating polar-functionalized polyolefins through copolymerization.

Despite recent research interest in phosphine-related ligands, imine-derived ligands are attractive platforms due to their many unique properties (e.g., easy to synthesize and modify). Moreover, phosphine-type ligands possess some drawbacks, such as high oxygen sensitivity as well as potential pyrophoricity and toxicity, that require special handling ${ }^{23}$. Interestingly, our literature survey indicates that the phosphine-based nickel catalysts (III-VII) typically lead to the formation of highly linear polyethylenes in ethylene polymerization ${ }^{24,25}$. In contrast, most $\mathrm{N}^{\wedge} \mathrm{N}$-based or $\mathrm{N}^{\wedge} \mathrm{O}$-based nickel catalysts (I, II, and many others) generate variously branched polyethylenes ${ }^{26-32}$. Industrially, branches are introduced through a-olefin copolymerization to improve the processability as well as many other material properties of polyolefins. The ability of these nitrogen-based nickel catalysts to produce branched polyethylenes using only ethylene as a feedstock is highly attractive from an industrial standpoint and has indeed led to extensive research efforts from large chemical companies, such as DuPont ${ }^{33}$. Based on these considerations as well as our ongoing efforts towards developing high-performance nickel catalysts, we became interested in the $\alpha$-imino-ketone ligand framework. Brookhart and co-workers briefly studied this type of ligand in a patent in $2000^{34}$. However, only moderate activity $\left(\sim 6.4 \times 10^{4} \mathrm{~g} \mathrm{~mol}^{-1} \mathrm{~h}^{-1}\right.$ at room temperature and 6.9 $\mathrm{MPa}$ of ethylene pressure) and moderate polyethylene molecular weights $\left(M_{\mathrm{n}}<80,000\right)$ were reported, and no studies on the influence of ligand structures or polymerization conditions were performed.

The synthesis of extensively studied $\alpha$-diimine ligands sometimes requires harsh reaction conditions along with very low yields. For example, Long and coworkers recently described the synthesis of sterically demanding $\mathrm{Ni}(\mathrm{II})$ a-diimine complex utilizing 2,6-bis(diphenyl-methyl)-4-methyl aniline, which is capable of producing polyethylene at temperatures up to $100^{\circ} \mathrm{C}$. However, very low yield (8.6\%) was reported for the $\alpha$-diimine ligand synthesis ${ }^{35}$. They subsequently reported a modified synthetic procedure for an acenaphthenequinone derived ligand, which still only led to $10 \%$ yield ${ }^{36}$. As a matter of fact, $\alpha$-iminoketone ligands are the key intermediate/side products during the synthesis of various $\alpha$-diimine ligands. It is somewhat surprising that they have not been extensively explored already. During our studies, it was observed that the reaction of $\alpha$-imino-ketone ligand with (DME) $\mathrm{NiBr}_{2}(\mathrm{DME}=$ ethylene glycol dimethyl ether) led to unstable nickel species. The addition of aluminum cocatalyst led to catalyst decomposition and no activity in ethylene polymerization. Comparing with $\alpha$-diimine ligand, $\alpha$-iminoketone ligand is electronically less donating and sterically less bulky, leading to a more nucleophilic and more sterically open metal center, which are beneficial for olefin monomer access and insertion. Unfortunately, these features also make it incapable of stabilizing a neutral nickel center $\left(\mathrm{NiBr}_{2}\right.$ for example). In this system, a pre-generated cationic nickel center $\left([\mathrm{Ni}(\mathrm{allyl})]^{+}\right)$was employed to address this issue. It should be noted that nickel allyl initiators are known in ethylene polymerization, but did not receive much attention ${ }^{37,38}$. Most studies using neutral ligands such as $\alpha$-diimine or pyridine-imine ${ }^{26,27}$ involved the synthesis of neutral (ligand) $\mathrm{NiBr}_{2}$ complexes, and the combination with aluminum cocatalyst generates active catalyst for olefin polymerization. Our preliminary studies showed that the combination of a-diimine or pyridine-imine ligands with the pre-generated cationic nickel center $\left([\mathrm{Ni}(\mathrm{allyl})]^{+}\right)$is also highly active in ethylene polymerization. We envision that this nickel allyl route provides an easy to handle, cheap and safe alternative versus the abovementioned traditional strategy.

In this contribution, we wish to demonstrate that a-iminoketone nickel is a highly versatile platform with many unique properties as follows: they are extremely easy to synthesize and
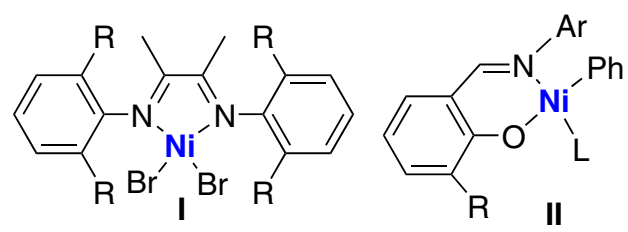<smiles></smiles><smiles>[R]c1cccc2c1O[N+](C)(C)P2(Br)(Br)Br</smiles>

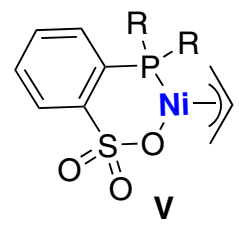

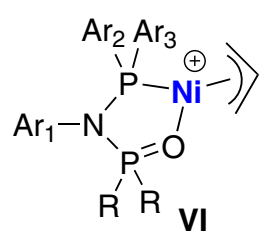
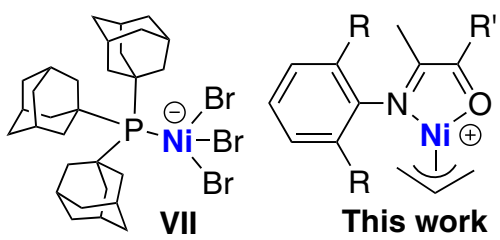

Fig. 1 Selected examples of nickel-based ethylene polymerization catalysts. Various high-performance ethylene (co)polymerization systems have been reported, with notable examples including $\alpha$-diimine nickel catalysts (I), salicylaldimine nickel catalysts (II), SHOP-type nickel catalysts (III), phosphinophenolate nickel catalysts (IV), phosphine-sulfonate nickel catalysts (V), diphosphazane monoxide nickel catalysts (VI), and triadamantylphosphine nickel catalysts (VII). In this work, a simple but extremely versatile $\alpha$-imino-ketone nickel system was reported. 


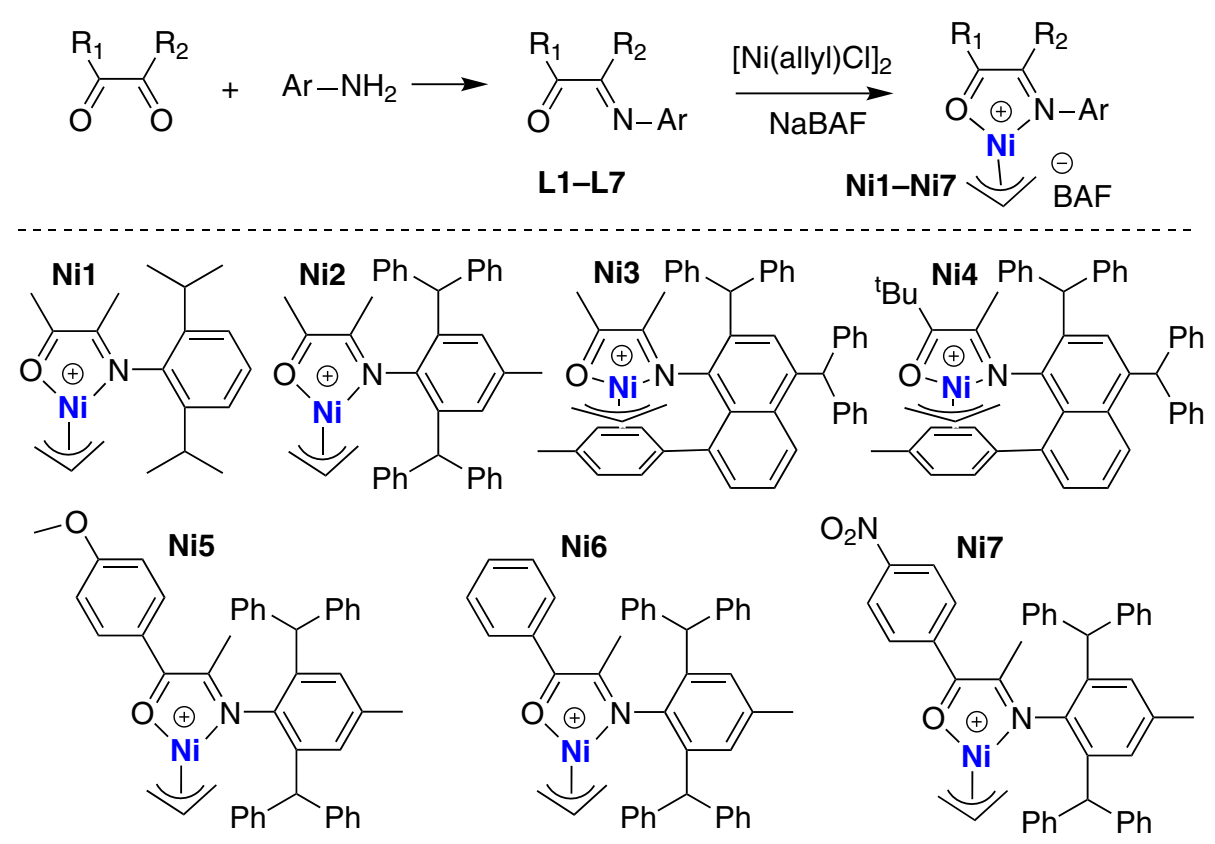

Fig. 2 Synthesis of $\alpha$-imino-ketone ligands and the corresponding nickel complexes. Reactions of diketone with anilines form $\alpha$-imino-ketone ligands (L1-L7). Reactions the ligands with $\left[\mathrm{Ni}\left(\right.\right.$ allyl) $\mathrm{Cl}_{2}$ and $\mathrm{NaBAF}$ form the desired cationic nickel complexes (Ni1-Ni7).

modify, making them potentially amenable for high-throughput screening experiments ${ }^{39}$; their single-component nature avoids the use of expensive and pyrophoric aluminum cocatalyst, which also eliminates chain transfer to the cocatalyst, to yield high molecular weight polymers and copolymers even at high polymerization temperatures; despite the sterically open nature, this class of nickel catalyst enables access to ultra-high-molecularweight polyethylene (UHMWPE, molecular weights: $10^{6}-10^{7}$ ), which is an important specialty class of polyethylene with wide applications ${ }^{40}$; and the versatility of this ligand platform allows facile synthesis of dinuclear counterpart and the installation of an anchor for catalyst heterogenization.

\section{Results}

Synthesis and characterization of the nickel complexes. The a-imino-ketone ligands can be easily prepared from the reactions of diketone with anilines at high yields (Fig. 2). In most cases, both reactants are commercially available or easily synthesized through simple reactions. The ligand framework is highly versatile with many positions that can be independently modified. Subsequently, the cationic nickel complexes (Ni1-Ni7) were obtained from the reactions of the ligands $(\mathbf{L} 1-\mathbf{L} 7)$ with $[\mathrm{Ni}(\text { allyl }) \mathrm{Cl}]_{2}$ and sodium tetrakis(3,5-bis(trifluoromethyl)phenyl)borate (NaBAF). These ligands and metal complexes were characterized by ${ }^{1} \mathrm{H}$ nuclear magnetic resonance (NMR), ${ }^{13} \mathrm{C}$ NMR, mass spectrometry and elemental analysis.

The molecular structures of Nil and Ni6 were determined by $\mathrm{X}$-ray diffraction analysis (Fig. 3). The geometry at the nickel center is square planar, making these nickel complexes diamagnetic and suitable for NMR characterization. A distinguishing feature of this system is the sterically open configuration that allows one side of the nickel center to be completely exposed, which is in direct contrast to the extensively studied Brookhart type $\alpha$-diimine nickel system. This configuration can lead to better accessibility of the nickel center, which may in turn increase catalytic activity as well as increase comonomer incorporation in copolymerization reactions. The calculated topographical steric map analyses ${ }^{41}$ confirmed that Nil is sterically much more open than an analogous $\alpha$-diimine-based nickel complex ${ }^{42}$ (buried volume $\% \mathrm{~V}_{\text {Bur }}$ of 39.9 vs. 46.6 , Supplementary Figs. 1, 2).

Ethylene polymerization studies. These nickel complexes are highly active in ethylene polymerization without the addition of any cocatalyst (Table 1). These nickel complexes demonstrated activities close to and more than $10^{8} \mathrm{~g} \mathrm{~mol}^{-1} \mathrm{~h}^{-1}$. In comparison to the iso-propyl-substituted catalyst Ni1, Ni2 bearing a sterically bulkier diphenyl-methyl substituent led to the formation of polyethylene with up to 9 times higher molecular weights (Table 1, entries 1-6). Most importantly, Ni2 is able to generate high molecular weight polyethylene even at $80^{\circ} \mathrm{C}$. Time dependence studies showed that Nil remained active for $30 \mathrm{~min}$ at $80^{\circ} \mathrm{C}$, and the thermal stability is comparable with the $\alpha$-diimine counterpart (Supplementary Fig. 3). The polymer molecular weight remained constant as the ethylene pressure increased (Table 1, entries 7-9). This result indicates that chain transfer to monomer is the predominant chain transfer pathway. Therefore, the propagation/chain transfer ratio is independent of the ethylene pressure ${ }^{43}$. Interestingly, the polymer branching density is largely independent of the ethylene pressure. In the a-diimine nickel system, the polymer molecular weight increased significantly along with a significantly decreased polymer branching density as the ethylene pressure increased ${ }^{44}$. This contrast may originate from the sterically open nature of the a-imino-ketone system compared to the a-diimine system.

The in situ mixing of the ligands with the nickel precursors (without isolation/purification of the nickel complex) led to the same polymerization properties compared to the discrete metal complexes. By changing the polymerization solvent from toluene to an industrially preferred hydrocarbon solvent, increased activity $\left(1.06 \times 10^{8} \mathrm{~g} \mathrm{~mol}^{-1} \mathrm{~h}^{-1}\right)$ along with a similar molecular weight were observed (Table 1, entry 10). These attractive features make this system potentially amenable to high-throughput screening experiments as well as continuous polymerization processes.

The utilization of substituted naphthalenyl amines ${ }^{45}$ led to reduced catalytic activities (Ni3 and Ni4). However, greatly increased polymer molecular weights were achieved. Specifically, 

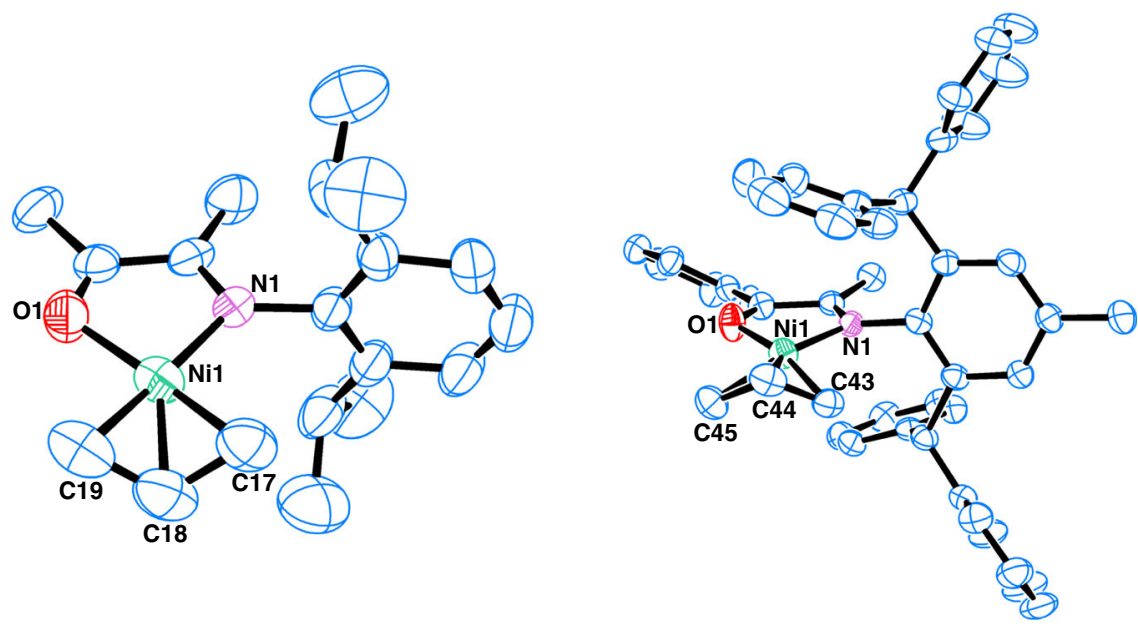

Fig. 3 Molecular structures of Ni1 and Ni6. Hydrogen atoms and BAF group were omitted for clarity. Selected bond lengths $(\AA)$ and angles $\left({ }^{\circ}\right)$ : Ni1-N1 $=$ 1.925(3), Ni1-O1=1.946(3), Ni1-C17 =1.98(8), Ni1-C18=1.916(18), Ni1-C19=1.95(7), N1-Ni1-O1=82.05(13), C19-Ni1-C17= 74(3); Ni1-C44=1.921 (14), Ni1-O1=1.923(4), Ni1-N1=1.942(4), Ni1-C43=2.01(5), Ni1-C45=2.03(2), O1-Ni1-N1=81.29(16), C43-Ni1-C45=72.3(17).

Table 1 Ethylene homopolymerization with Ni complexes.

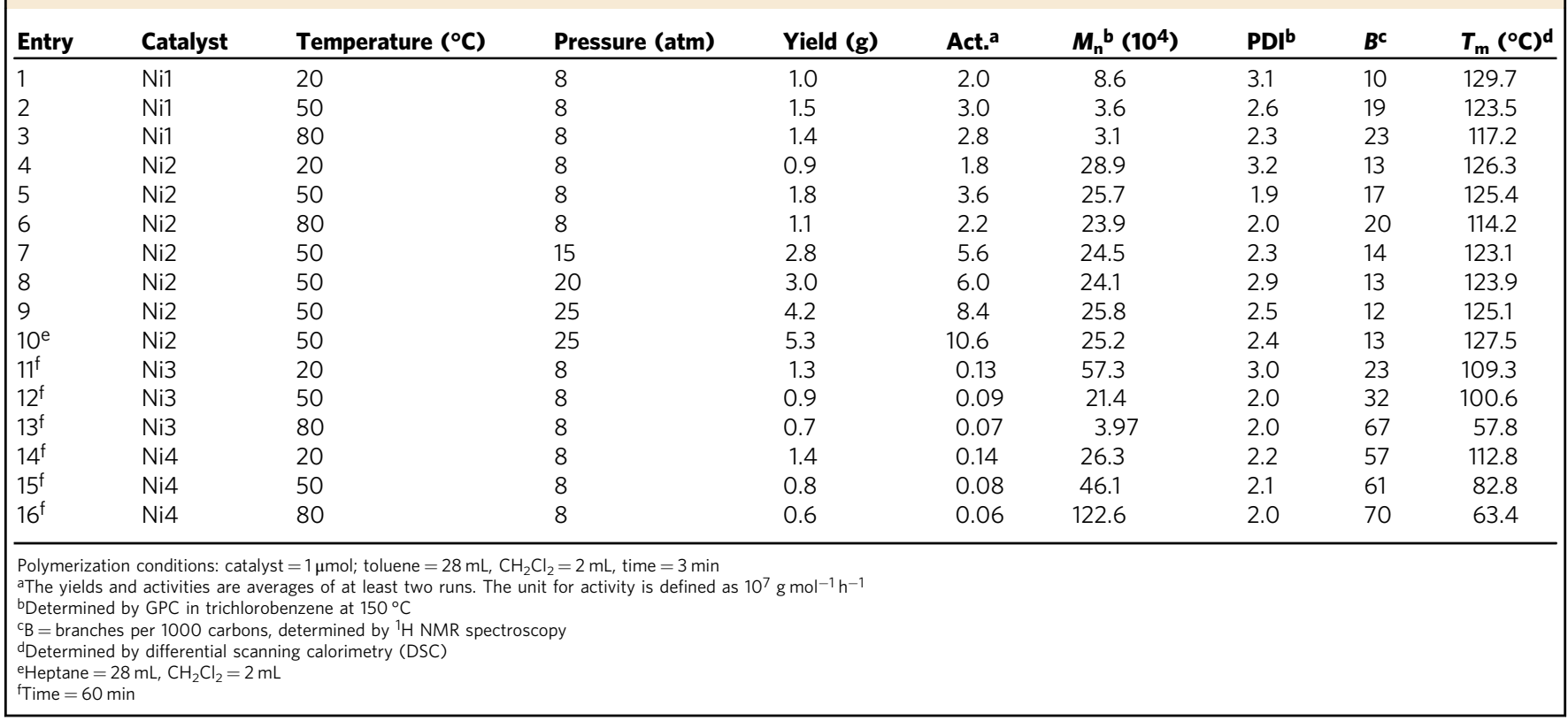

polyethylene with a molecular weight of more than one million can be generated by $\mathbf{N i 4}$ at $80^{\circ} \mathrm{C}$. Interestingly, $\mathrm{Ni3} / \mathrm{Ni4}$ afforded polyethylenes with much higher branching densities (23-70/1000 C) than those obtained from Ni1/Ni2. The electronic effect of the ketone side was investigated using complexes Ni5-Ni7 (Supplementary Table 1). Complexes Ni5-Ni7 exhibited high activities $\left(1.2-2.6 \times 10^{7} \mathrm{~g} \mathrm{~mol}^{-1} \mathrm{~h}^{-1}\right)$ that are comparable to those of Ni1/Ni2. In addition, polyethylenes with very high molecular weights $\left(M_{\mathrm{n}}\right.$ up to $\left.8.19 \times 10^{5}\right)$ were generated even at high temperatures. Specifically, complex Ni7 bearing an electronwithdrawing substituent (i.e., $\mathrm{NO}_{2}$ ) resulted in greatly reduced polymer branching densities $(5-8 / 1000 \mathrm{C})$ and increased melting points $\left(124.7-129.5^{\circ} \mathrm{C}\right)$ compared to those of $\mathrm{Ni5}$ and $\mathrm{Ni6}$ (12-23/1000 C and $110.8-122.8^{\circ} \mathrm{C}$, respectively).

Ethylene-polar monomer copolymerization studies. Nickel catalysts based on $\alpha$-diimine ligands can enable copolymerization reaction of ethylene with methyl acrylate (MA) ${ }^{46}$. However, very harsh polymerization conditions $\left(120^{\circ} \mathrm{C}\right.$ and 1000 psi ethylene pressure) and a large amount of tris(pentafluorophenyl)borane additive were required. In this system, moderate activity and copolymer molecular weight were achieved under mild conditions without the addition of any cocatalyst or protecting agent (Table 2, entry 1). Very high activity and high incorporation (10.8\%) were observed with trimethoxyvinylsilane (Table 2, entry 2), indicating the low poisoning effect of this type of comonomer 47,48 . 5-norbornene-2-yl acetate is also suitable comonomer for copolymerization (Table 2, entry 3 ).

This catalytic system is particularly suitable for ethylene copolymerization with special comonomers bearing long spacers between the double bond and the polar groups. This system demonstrated high activities (up to $2.5 \times 10^{5} \mathrm{~g} \mathrm{~mol}^{-1} \mathrm{~h}^{-1}$ ), very high copolymer molecular weights $\left(M_{\mathrm{n}}\right.$ up to 306,700$)$ and high comonomer incorporation (1.8-6.3\%) towards comonomers 
Table 2 Ethylene copolymerizations with polar monomers with Ni complexes.

\begin{tabular}{|c|c|c|c|c|c|c|c|c|c|c|}
\hline Entr & ataly & Comonomer & $\begin{array}{c}\text { Temperature } \\
\left({ }^{\circ} \mathrm{C}\right)\end{array}$ & $\begin{array}{c}{[\mathrm{M}]} \\
\mathrm{mol} / \mathrm{L}\end{array}$ & $\begin{array}{l}\text { Yield } \\
(\mathrm{g})\end{array}$ & Act. ${ }^{b}$ & $X_{\mathrm{M}}^{\mathrm{c}}(\%)$ & $M_{\mathrm{n}}^{\mathrm{d}}$ & $\mathrm{PDI}^{\mathrm{d}}$ & $\begin{array}{c}T_{\mathrm{m}} \\
\left({ }^{\circ} \mathrm{C}\right)^{\mathrm{e}}\end{array}$ \\
\hline 1 & $\mathrm{Ni2}$ & $\widehat{\gamma}_{\mathrm{COOMe}}$ & 50 & 0.5 & 0.1 & 0.25 & 0.6 & 17900 & 2.0 & 124.9 \\
\hline 2 & $\mathrm{Ni} 2$ & ${\widehat{\mathrm{Si}}(\mathrm{OMe})_{3}}$ & 50 & 1 & 8.8 & 22 & 10.8 & 8300 & 5.4 & 104.0 \\
\hline 3 & $\mathrm{Ni} 2$ & $\Delta y_{0}^{0}$ & 50 & 1 & 0.3 & 0.8 & 5.5 & 29000 & 1.7 & 96.2 \\
\hline 4 & $\mathrm{Ni} 2$ & $\mathrm{Xr}_{4}^{\mathrm{Cl}}$ & 50 & 1 & 2.3 & 5.8 & 2.2 & 306700 & 2.4 & 109.3 \\
\hline 5 & $\mathrm{Ni} 2$ & $-\mathrm{Xr}_{4}^{\mathrm{Cl}}$ & 50 & 2 & 2.0 & 5.0 & 3.4 & 151800 & 1.8 & 102.5 \\
\hline 6 & $\mathrm{Ni} 2$ & $\mathrm{X}_{8}^{\mathrm{coOM} e}$ & 20 & 1 & 4.0 & 10 & 2.8 & 72200 & 1.6 & 109.8 \\
\hline 7 & $\mathrm{Ni3}$ & $-x_{8}^{\text {coOMe }}$ & 20 & 1 & 2.0 & 5.0 & 2.8 & 55500 & 1.6 & 109.6 \\
\hline 8 & $\mathrm{Ni4}$ & $-\mathrm{Xt}_{8}^{\mathrm{coOMe}}$ & 20 & 1 & 5.3 & 13.3 & 1.8 & 165200 & 1.8 & 95.9 \\
\hline 9 & $\mathrm{Ni2}$ & $-\mathrm{Xt}_{8}^{\mathrm{coOMe}}$ & 50 & 1 & 10 & 25 & 3.2 & 50100 & 2.0 & 110.6 \\
\hline 10 & $\mathrm{Ni} 2$ & $\mathrm{CH}_{8}^{\mathrm{COOMe}}$ & 50 & 2 & 7.0 & 17.5 & 6.3 & 33300 & 1.8 & 95.0 \\
\hline
\end{tabular}

Polymerization conditions: total volume of toluene and polar monomer $=20 \mathrm{~mL}$, catalyst $=20 \mu \mathrm{mol}$, time $=2 \mathrm{~h}$

aThe yields and activities are averages of at least two runs. The unit for activity is defined as $10^{4} \mathrm{~g} \mathrm{~mol}^{-1} \mathrm{~h}^{-1}$

betermined by ${ }^{1} \mathrm{H}$ NMR integration in $\mathrm{C}_{2} \mathrm{D}_{2} \mathrm{Cl}_{4}$ at $120^{\circ} \mathrm{C}$

CDetermined by GPC in trichlorobenzene at $150^{\circ} \mathrm{C}$

dDetermined by DSC

6-chloro-1-hexene and methyl 10-undecenoate (Table 2, entries 4-10). Methyl 10-undecenoate has the added advantage of being biorenewable and readily available from cross metathesis using fatty acid derivatives, such as methyl oleate ${ }^{49}$. These superior features make this approach an efficient route to access polarfunctionalized linear low-density polyethylene (LLDPE) ${ }^{50}$. In previously reported ethylene-polar monomer copolymerization studies, a high comonomer concentration is required to achieve high incorporation, which leads to a very low comonomer utilization ratio. The most distinguishing feature of this system is the high comonomer utilization ratio $(47.8 \%$ and $28.5 \%$ of methyl 10 -undecenoate were consumed for entries 9 and 10, respectively). This ratio can be further improved through optimization of catalyst structures and polymerization conditions. Consistent with the above-mentioned studies, this unique feature is probably due to the sterically open nature of the a-imino-ketone system.

Dinuclear nickel complexes. The metal-metal cooperativity effect has been demonstrated to be a powerful strategy to mediate the olefin polymerization processes ${ }^{51}$. However, the design and synthesis of dinuclear metal complexes can be complicated and time consuming. Due to the structural simplicity of the $a$-iminoketone platform, dinucleating ligands can be easily prepared starting from various di-amines. Here, a dinuclear nickel complex (Fig. 4, Ni-Ni) was prepared using a xanthene-bridged diamine ${ }^{52,53}$. In comparison to the mono-nuclear analog (Ni1), Ni-Ni exhibited similar activities, increased polymer molecular weights and reduced polyethylene branching densities (Table 3, entries 1-3).

Heterogeneous nickel complex. Heterogeneous olefin polymerization catalysts are preferred from an industrial perspective due to their ability to control product morphology, preventing reactor fouling and enabling continuous polymerization process $^{54}$. The heterogenization of early transition metal catalysts has been extensively studied, and many systems have been successfully commercialized ${ }^{55,56}$. In comparison, very few studies on the heterogenization of late transition metal catalysts have been
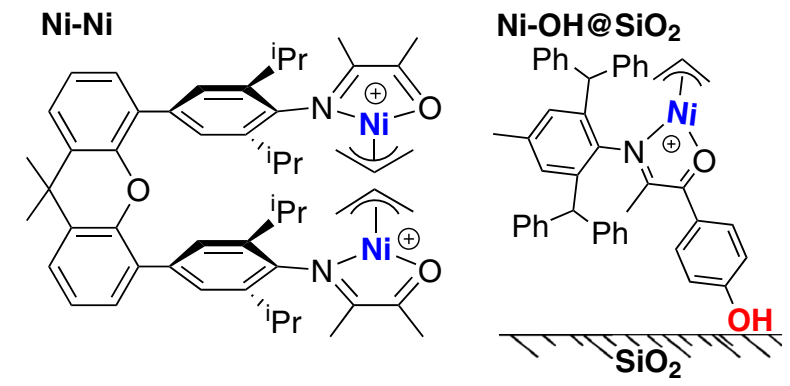

Fig. 4 Chemical structures of the dinuclear and supported nickel complexes. A dinuclear nickel complex (Ni-Ni) was prepared from a xanthene-bridged di-amine. $\mathrm{A} \mathrm{SiO}_{2}$ supported nickel complex (Ni-OH@SiO $\mathbf{S}_{2}$ )was generated from the interaction of a pre-installed anchoring group $(\mathrm{OH})$ with the solid support.

reported $^{57-61}$. A homogeneous catalyst supported on a solid support can lead to serious steric crowding and complications due to side reactions, which could greatly reduce catalytic activities ${ }^{62}$. In some cases, the support of homogeneous catalyst would limit monomer access to the metal center, thereby decreasing polymerization activity. Due to the single-component and sterically open characteristics of this type of catalysts, we envision that a straightforward process for heterogenization on a $\mathrm{SiO}_{2}$ support. Unfortunately, these nickel catalysts exhibited very low affinity for the $\mathrm{SiO}_{2}$ support despite their cationic nature. In most previous heterogenization studies, the $\mathrm{SiO}_{2}$ support must be pretreated with an aluminum type of cocatalyst, such as methylaluminoxane, to increase the affinity of the metal complex for the solid support ${ }^{62,63}$. Furthermore, a large amount of additional cocatalyst is required to achieve high catalytic activity. In this study, we utilized an alternative strategy to address this issue through the installation of an anchoring group $(\mathrm{OH})$ onto the catalyst. Indeed, the corresponding $\mathbf{N i -} \mathbf{O H}$ complex can be easily supported on $\mathrm{SiO}_{2}$, leading to a highly active heterogeneous 
Table 3 Ethylene homopolymerization with Ni complexes.

\begin{tabular}{|c|c|c|c|c|c|c|c|c|c|}
\hline Entry & Catalyst & Temperature $\left({ }^{\circ} \mathrm{C}\right)$ & Pressure (atm) & Yield (g) & Act. $^{a}$ & $M_{n}^{b}\left(10^{4}\right)$ & PDIb & $B^{C}$ & $T_{m}\left({ }^{\circ} \mathrm{C}\right)^{d}$ \\
\hline 1 & $\mathrm{Ni}-\mathrm{Ni}$ & 20 & 8 & 0.7 & 1.4 & 12.9 & 2.0 & 8 & 131.1 \\
\hline 2 & $\mathrm{Ni}-\mathrm{Ni}$ & 50 & 8 & 1.0 & 2.0 & 4.7 & 1.7 & 16 & 123.6 \\
\hline 3 & $\mathrm{Ni}-\mathrm{Ni}$ & 80 & 8 & 0.8 & 1.6 & 4.0 & 1.8 & 22 & 119.8 \\
\hline 4 & $\mathrm{Ni}-\mathrm{OH}$ & 20 & 8 & 0.8 & 1.6 & 104.3 & 1.8 & 15 & 124.6 \\
\hline 5 & $\mathrm{Ni}-\mathrm{OH}$ & 50 & 8 & 0.7 & 1.4 & 54.4 & 2.4 & 16 & 116.6 \\
\hline 6 & $\mathrm{Ni}-\mathrm{OH}$ & 80 & 8 & 0.6 & 1.2 & 48.2 & 2.4 & 16 & 114.3 \\
\hline 7 & $\mathrm{Ni}-\mathrm{OH}$ & 100 & 8 & 0.35 & 0.7 & 23.4 & 2.4 & 18 & 113.9 \\
\hline $8^{e}$ & $\mathrm{Ni}-\mathrm{OH}$ & 100 & 8 & 0.5 & 0.1 & 22.6 & 2.3 & 17 & 115.6 \\
\hline $9^{f}$ & $\mathrm{Ni}-\mathrm{OH} @ \mathrm{SiO}_{2}$ & 50 & 8 & 2.2 & 0.44 & 155.6 & 2.7 & 10 & 129.9 \\
\hline $10^{f}$ & $\mathrm{Ni}-\mathrm{OH} @ \mathrm{SiO}_{2}$ & 80 & 8 & 1.1 & 0.22 & 72.2 & 3.0 & 11 & 126.4 \\
\hline $11^{f}$ & $\mathrm{Ni}-\mathrm{OH} @ \mathrm{SiO}_{2}$ & 100 & 8 & 0.8 & 0.16 & 70.1 & 2.9 & 16 & 122.7 \\
\hline $12^{f}$ & $\mathrm{Ni}-\mathrm{OH} @ \mathrm{SiO}_{2}$ & 50 & 15 & 2.8 & 0.56 & 159.3 & 3.0 & 11 & 131.1 \\
\hline $13^{f}$ & $\mathrm{Ni}-\mathrm{OH} @ \mathrm{SiO}_{2}$ & 50 & 20 & 3.2 & 0.64 & 146.5 & 2.9 & 10 & 131.1 \\
\hline $14^{f}$ & $\mathrm{Ni}-\mathrm{OH} @ \mathrm{SiO}_{2}$ & 50 & 25 & 4.0 & 0.8 & 144.4 & 2.4 & 9 & 131.9 \\
\hline \multicolumn{10}{|c|}{$\begin{array}{l}\text { Polymerization conditions: catalyst }=1 \mu \mathrm{mol} \text {; toluene }=28 \mathrm{~mL}, \mathrm{CH}_{2} \mathrm{Cl}_{2}=2 \\
\text { aThe yields and activities are average of at least two runs. The unit for a } \\
\text { bDetermined by } \mathrm{GPC} \text { in trichlorobenzene at } 150^{\circ} \mathrm{C} \\
{ }^{\mathrm{C}} \mathrm{B}=\text { branches per } 1000 \text { carbons, determined by }{ }^{1} \mathrm{H} \text { NMR spectroscopy } \\
\text { dDetermined by differential scanning calorimetry (DSC) } \\
\text { eTime }=30 \mathrm{~min} \\
{ }^{\mathrm{f} T i m e}=30 \mathrm{~min} \text {, Heptane }=30 \mathrm{~mL}\end{array}$} \\
\hline
\end{tabular}

catalyst (Fig. 4). Using this approach, pretreatment of the solid support or use of any cocatalyst can be avoided.

Homogeneous complex Ni-OH exhibited very high activities $\left(1.6 \times 10^{7} \mathrm{~g} \mathrm{~mol}^{-1} \mathrm{~h}^{-1}\right)$ for ethylene polymerization, generating polyethylene with molecular weights of more than one million (Table 3, entries 4-8). The ability of complexes $\mathbf{N i 4}$ and $\mathbf{N i}-\mathbf{O H}$ to generate UHMWPE is quite surprising considering their sterically open characteristics. The synthesis of UHMWPE using nickel catalysts remains challenging, and very few nickel systems have these capabilities ${ }^{64-70}$. Furthermore, it is even more challenging to develop heterogeneous nickel catalyst with such capabilities, and to the best of our knowledge, this type of system has not been reported previously.

The supported catalyst $\mathbf{N i}-\mathbf{O H} @ \mathrm{SiO}_{2}$ exhibited greatly increased polymerization activity compared to its homogeneous counterpart. In addition, polyethylene with substantially enhanced molecular weights and slightly decreased branching densities were generated (Table 3, entries 9-11). The polymerization activities slightly increased with increasing ethylene pressure (Table 3, entries 12-14). In addition, the polyethylene molecular weights and polymer branching densities remained constant, which is similar to the results for homogeneous catalyst Ni2. $\mathbf{N i - O H @ S i O} \mathbf{O}_{2}$ is able to generate polyethylene with molecular weights of much higher than one million $\left(M_{\mathrm{n}}\right.$ up to $\left.1.593 \times 10^{6}\right)$. Most surprisingly, high molecular weight polyethylene $\left(M_{\mathrm{n}}=\right.$ $7.01 \times 10^{5}$ ) can be obtained even at $100^{\circ} \mathrm{C}$, demonstrating the superior properties of heterogeneous catalyst $\mathrm{Ni}-\mathrm{OH} @ \mathrm{SiO}_{2}$. Interestingly, $\mathbf{N i - O H @ S i O} \mathbf{S}_{2}$ generated polyethylenes with more linear microstructure and higher melting points compared to those of the homogeneous counterpart Ni-OH. Probably, the interaction of the $\mathrm{OH}$ moiety on the ligand backbone with the $\mathrm{SiO}_{2}$ surface alters the electronic environment around the nickel center, influencing the polymerization properties.

The results from time dependent studies indicate that heterogeneous catalyst $\mathbf{N i - O H @ S i O}{ }_{2}$ is thermally much more stable than the homogeneous counterpart $\mathbf{N i - O H}$ (Fig. 5, Supplementary Table 2). Significant decomposition was observed for $\mathbf{~ N i - O H}$ after $3 \mathrm{~min}$ at $100^{\circ} \mathrm{C}$ (Fig. 5; Table 3, entries 7 and 8). In contrast, $\mathbf{N i - O H @ S i O}{ }_{2}$ remained highly active within $2 \mathrm{~h}$ at $100{ }^{\circ} \mathrm{C}$. More importantly, $\mathbf{N i}-\mathbf{O H} @ \mathrm{SiO}_{2}$ led to the formation of while powders while $\mathbf{N i}-\mathbf{O H}$ led to greenish products, clearly indicating catalyst decomposition (Supplementary Fig. 4).

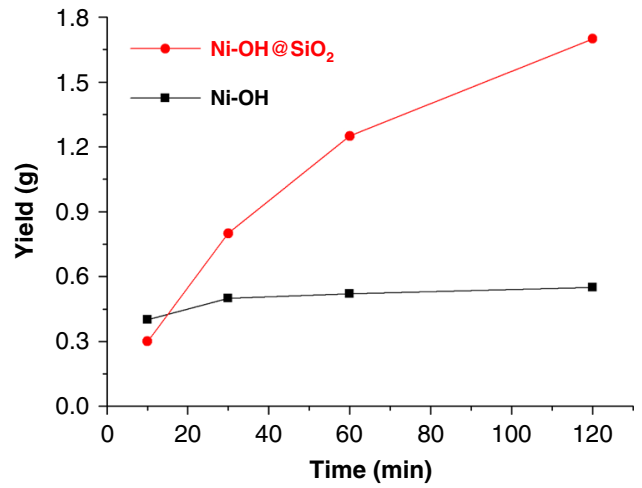

Fig. 5 Polymer yield as a function of time for $\mathrm{Ni}-\mathrm{OH} @ \mathrm{SiO}_{2}$ and $\mathrm{Ni}-\mathrm{OH}$. $\mathbf{N i}-\mathbf{O H} @ \mathbf{S i O}_{\mathbf{2}}$ is thermally more stable than $\mathbf{N i -}-\mathbf{O H}$ in ethylene polymerization at $100^{\circ} \mathrm{C}$, and remained highly active within $120 \mathrm{~min}$ (homogeneous polymerization conditions: ethylene $=8 \mathrm{~atm}$, catalyst $=$ $1 \mu \mathrm{mol}$, heptane $=29 \mathrm{~mL}, \mathrm{DCM}=1 \mathrm{~mL}$; heterogeneous polymerization conditions: ethylene $=8 \mathrm{~atm}$, catalyst $=1 \mu \mathrm{mol}$ catalyst supported on $100 \mathrm{mg}$ of $\mathrm{SiO}_{2}$, heptane $=30 \mathrm{~mL}$ ).

Furthermore, Ni-OH led to the formation of an agglomerated polymer product that sticks to the polymerization vessel. However, Ni-OH@SiO 2 yielded free-flowing polymer particles (Supplementary Fig. 5). The polymer particles increase in size along with polymerization time, and replicate the shape of the starting silica particles (Supplementary Fig. 6). These superior features make the heterogeneous system highly attractive and suitable for an industrially preferred continuous process.

\section{Discussion}

A simple but versatile $\alpha$-imino-ketone nickel system has been demonstrated to exhibit great properties for ethylene polymerization and copolymerization with polar monomers. Despite their sterically open nature, these nickel catalysts are thermally stable with the ability to generate polymers with very high molecular weights and tunable branching densities. To further demonstrate the versatility of this system, a dinucleating ligand was designed to utilize the metal-metal cooperativity effect and 
an anchoring moiety was introduced to facilitate heterogenization of the homogeneous nickel catalyst. This system combines many superior properties, such as ease of synthesis, single component nature, high thermal stability, generation of high molecular weight polymers and simplicity in heterogenization and modification, making it highly attractive for future investigations.

\section{Methods}

Measurements. All experiments were carried out under dry Nitrogen atmosphere using standard Schlenk techniques or in a glove-box. Deuterated solvents used for NMR were dried and distilled prior to use. ${ }^{1} \mathrm{H},{ }^{13} \mathrm{C}$ NMR spectra were recorded a Bruker Ascend ${ }^{\mathrm{Tm}} 400$ spectrometer at ambient temperature unless otherwise stated. The chemical shifts of the ${ }^{1} \mathrm{H}$ and ${ }^{13} \mathrm{C}$ NMR spectra were referenced to tetramethylsilane. Coupling constants are in $\mathrm{Hz}$. Elemental analysis was performed by the Analytical Center of the University of Science and Technology of China. X-ray diffraction data were collected at 298 (2) K on a Bruker Smart CCD area detector with graphite-monochromated Mo Ka radiation $(\lambda=0.71073 \AA)$. Molecular weights and molecular weight distributions of the polymers were determined by gel permeation chromatography (GPC) using an Agilent PL-220 chromatograph equipped with two Agilent PLgel Olexis columns operating at $150^{\circ} \mathrm{C}$ using o-dichlorobenzene as the solvent. The system was calibrated with a polystyrene standard, and chromatograms were corrected for linear polyethylene through universal calibration using the Mark-Houwink parameters of Rudin: $K=1.75 \times$ $10^{-2} \mathrm{~cm}^{3} / \mathrm{g}$ and $R=0.67$ for polystyrene, and $K=5.90 \times 10^{-2} \mathrm{~cm}^{3} / \mathrm{g}$ and $R=0.69$ for polyethylene. Dichloromethane, hexanes, and toluene were purified by solvent purification systems. $955 \mathrm{SiO}_{2}$ was purchased from Grace Davison Co., Ltd. (average pore diameter $=22.6 \mathrm{~nm}$, surface area $=264 \mathrm{~m}^{2} / \mathrm{g}$, average particle size $=$ $40 \mu \mathrm{m})$. The silica was activated at $600^{\circ} \mathrm{C}$ for $5 \mathrm{~h}$ before use.

Procedure for ethylene homopolymerization. In a typical experiment, a $350 \mathrm{~mL}$ pressure vessel was charged with $28 \mathrm{~mL}$ toluene or $28 \mathrm{~mL}$ heptane, the catalyst sample (supported nickel complex or nickel complex solution in dichloromethane) and a magnetic stir bar in the glovebox. The pressure vessel was connected to a high pressure line and the solution was degassed. The vessel was warmed to setting temperature using an oil bath (water bath for the case of polymerization at room temperature) and allowed to equilibrate for $15 \mathrm{~min}$. With rapid stirring, the reactor was pressurized and maintained at $8.0 \mathrm{~atm}$ of ethylene. After desired amount of time, the pressure vessel was vented and the polymer was precipitated in methanol and dried at $50^{\circ} \mathrm{C}$ for $24 \mathrm{~h}$ under vacuum.

Procedure for ethylene-polar monomer copolymerization. In a typical experiment, a $350 \mathrm{~mL}$ pressure vessel was charged with toluene and polar monomer in total $18 \mathrm{~mL}$ and a magnetic stir bar in the glovebox. The pressure vessel was connected to a high pressure line and the solution was degassed. The vessel was warmed to $50^{\circ} \mathrm{C}$ using an oil bath (water bath for the case of polymerization at room temperature) and allowed to equilibrate for $15 \mathrm{~min}$. Twenty micromolar of $\mathrm{Ni}$ complex in $2 \mathrm{~mL} \mathrm{CH} \mathrm{Cl}_{2}$ was injected into the polymerization system via syringe. With rapid stirring, the reactor was pressurized and maintained at $8.0 \mathrm{~atm}$ of ethylene. After $2 \mathrm{~h}$, the pressure vessel was vented and the polymer was precipitated in methanol and dried at $50^{\circ} \mathrm{C}$ for $24 \mathrm{~h}$ under vacuum.

\section{Data availability}

The X-ray crystallographic data for complex Nil has been deposited at the Cambridge Crystallographic Data Center (CCDC) under the deposition number 1828966. The X-ray crystallographic data for complex Ni6 has been deposited at the Cambridge Crystallographic Data Center (CCDC) under the deposition number 1814000. These data can be obtained free of charge via www.ccdc.cam.ac.uk/data_request/cif. Supplementary Information contains detailed experimental procedures and characterization data for new compounds ((Supplementary Methods), as well as DSC (Supplementary Figs. 103-151), GPC (Supplementary Figs. 152-200), X-ray crystallography (Supplementary Table 3 and Supplementary Table 4), ${ }^{13} \mathrm{C}$ and ${ }^{1} \mathrm{H}$ NMR data (Supplementary Figs. $7-46$ and Supplementary Figs. 54-102), ESI-MS (Supplementary Figs. 47-53). All data can be supplied by the authors upon reasonable request.

Received: 19 October 2019; Accepted: 11 December 2019; Published online: 17 January 2020

\section{References}

1. Chen, C. Designing catalysts for olefin polymerization and copolymerization: beyond electronic and steric tuning. Nat. Rev. Chem. 2, 6-14 (2018).

2. Gao, Y. S. et al. Highly branched polyethylene oligomers via group IVcatalysed polymerization in very nonpolar media. Nat. Catal. 2, 236-242 (2019).
3. Eagan, J. M. et al. Combining polyethylene and polypropylene: enhanced performance with PE/iPP multiblock polymers. Science 355, 814-816 (2017).

4. Guan, Z., Cotts, P. M., McCord, E. F. \& McLain, S. J. Chain walking: a new strategy to control polymer topology. Science 283, 2059-2062 (1999).

5. Ziegler, K. A Forty Years' Stroll through the realms of organometallic chemistry. Adv. Organomet. Chem. 6, 1-17 (1968).

6. Wilke, G. Fifty years of Ziegler catalysts: consequences and development of an invention. Angew. Chem. Int. Ed. 42, 5000-5008 (2003).

7. Johnson, L. K., Killian, C. M. \& Brookhart, M. New Pd(II)- and Ni(II)-Based catalysts for polymerization of ethylene and a-olefins. J. Am. Chem. Soc. 7, 6414-6415 (1995).

8. Kaiser, J. M. \& Long, B. K. Recent developments in redox-active olefin polymerization catalysts. Coord. Chem. Rev. 372, 141-152 (2018).

9. Wang, F. Z. \& Chen, C. L. A continuing legend: the Brookhart-type a-diimine nickel and palladium catalysts. Polym. Chem. 10, 2354-2369 (2019).

10. Younkin, T. R. et al. Neutral, single-component nickel (II) polyolefin catalysts that tolerate heteroatoms. Science 287, 460-462 (2000).

11. Radlauer, M. R., Buckley, A. K., Henling, L. M. \& Agapie, T. Bimetallic coordination insertion polymerization of unprotected polar monomers: copolymerization of amino olefins and ethylene by dinickel bisphenoxyiminato catalysts. J. Am. Chem. Soc. 135, 3784-3787 (2013).

12. Takeuchi, D., Chiba, Y., Takano, S. \& Osakada, K. Double-Decker-type dinuclear nickel catalyst for olefin polymerization: efficient incorporation of functional co-monomers. Angew. Chem. Int. Ed. 52, 12536-12540 (2013).

13. Cai, Z., Xiao, D. \& Do, L. H. Fine-tuning nickel phenoxyimine olefin polymerization catalysts: performance boosting by alkali cations. J. Am. Chem. Soc. 137, 15501-15510 (2015).

14. Chiu, H.-C., Koley, A., Dunn, P. L., Hue, R. J. \& Tonks, I. A. Ethylene polymerization catalyzed by bridging $\mathrm{Ni} / \mathrm{Zn}$ heterobimetallic. Dalton Trans. 46, 5513-5517 (2017).

15. Keim, W. Oligomerization of ethylene to a-olefins: discovery and development of the shell higher olefin process (SHOP). Angew. Chem. Int. Ed. 52, 12492-12496 (2013).

16. Kuhn, P., Semeril, D., Matt, D., Chetcuti, M. J. \& Lutz, P. Structure-reactivity relationships in SHOP-type complexes: tunable catalysts for the oligomerisation and polymerisation of ethylene. Dalton Trans. 5, 515-528 (2007).

17. Xin, B. S. et al. Nickel catalyzed copolymerization of ethylene and alkyl acrylates. J. Am. Chem. Soc. 139, 3611-3614 (2017).

18. Zhang, Y. P., Mu, H. L., Pan, L., Wang, X. L. \& Li, Y. S. Robust bulky $[\mathrm{P}, \mathrm{O}]$ neutral nickel catalysts for copolymerization of ethylene with polar vinyl monomers. ACS Catal. 8, 5963-5976 (2018).

19. Chen, M. \& Chen, C. L. Rational design of high-performance phosphine sulfonate nickel catalysts for ethylene polymerization and copolymerization with polar monomers. ACS Catal. 7, 1308-1312 (2017).

20. Chen, M. \& Chen, C. A versatile ligand platform for palladium- and Nickelcatalyzed ethylene copolymerizations with polar monomers. Angew. Chem. Int. Ed. 57, 3094-3098 (2018)

21. Kocen, A., Brookhart, M. \& Daugulis, O. A highly active Ni(II)triadamantylphosphine catalyst for ultrahigh-molecular-weight polyethylene synthesis. Nat. Commun. 10, 438 (2019).

22. Tao, W. J., Nakano, R., Ito, S. \& Nozaki, K. Copolymerization of ethylene and polar monomers by using Ni/IzQO catalysts. Angew. Chem. Int. Ed. 55, 2835-2839 (2016).

23. Stockland, R. A. Practical Functional Group Synthesis (Wiley, Waukegan, IL, 2016).

24. Mu, H. L., Pan, L., Song, D. P. \& Li, Y. S. Neutral nickel catalysts for olefin homo- and copolymerization: relationships between catalyst structures and catalytic properties. Chem. Rev. 115, 12091-12137 (2015).

25. Tan, C. \& Chen, C. L. Emerging palladium and nickel catalysts for copolymerization of clefins with polar monomers. Angew. Chem. Int. Ed. 58, 7192-7200 (2019).

26. Campora, J. \& Giambastiani, G. Olefin Upgrading Catalysis by Nitrogen-based Metal Complexes I (Springer, 2011)

27. Giambastiani, G. \& Campora, J. Olefin Upgrading Catalysis by Nitrogen-based Metal Complexes II (Springer, 2011)

28. Dai, S. Y., Sui, X. L. \& Chen, C. L. Synthesis of high molecular weight polyethylene using iminopyridyl nickel catalysts. Chem. Commun. 52, 9113-9116 (2016)

29. Gao, J. X., Yang, B. P. \& Chen, C. L. Sterics versus electronics: imine/ phosphine-oxide-based nickel catalysts for ethylene polymerization and copolymerization. J. Catal. 369, 233-238 (2019).

30. Long, B. K., Eagan, J. M., Mulzer, M. \& Coates, G. W. Semi-crystalline polar polyethylene: ester-functionalized linear polyolefins enabled by a functionalgroup-tolerant, cationic nickel catalyst. Angew. Chem. Int. Ed. 55, 7106-7110 (2016).

31. Fu, X., Zhang, L. J., Tanaka, R., Shiono, T. \& Cai, Z. G. Highly robust nickel catalysts containing anilinonaphthoquinone ligand for copolymerization of ethylene and polar monomers. Macromolecules 50, 9216-9221 (2017). 
32. Zhong, L., Li, G. L., Liang, G. D., Gao, H. Y. \& Wu, Q. Enhancing thermal stability and living fashion in $\alpha$-diimine-nickel-catalyzed (co)polymerization of ethylene and polar monomer by increasing the steric bulk of ligand backbone. Macromolecules 50, 2675-2682 (2017).

33. Tullo, A. H. Single-site success. Chem. Eng. News 79, 35-36 (2001).

34. Brookhart, M. et al. Polymerization of olefinic compounds. Patent WO2002059165 (2002)

35. Rhinehart, J. L., Brown, L. A. \& Long, B. K. A robust Ni (II) $\alpha$-diimine catalyst for high temperature ethylene polymerization. J. Am. Chem. Soc. 135 16316-16319 (2013).

36. Rhinehart, J. L., Mitchell, N. E. \& Long, B. K. Enhancing a-diimine catalysts for high-temperature ethylene polymerization. ACS Catal. 4, 2501-2504 (2014).

37. Boardman, B. M. \& Bazan, G. C. $\alpha$-Iminocarboxamidato nickel complexes. Acc. Chem. Res. 42, 1597-1606 (2009).

38. Chen, M., Zou, W., Cai, Z. \& Chen, C. Norbornene homopolymerization and copolymerization with ethylene by phosphine-sulfonate nickel catalysts. Polym. Chem. 6, 2669-2676 (2015).

39. Arriola, D. J., Carnahan, E. M., Hustad, P. D., Kuhlman, R. L. \& Wenzel, T. T. Catalytic production of olefin block copolymers via chain shuttling polymerization. Science 312, 714-719 (2006).

40. Kurtz, S. M. UHMWPE Biomaterials Handbook 7-20 (Elsiever, London, 2016).

41. Falivene, L. et al. SambVca 2. A web tool for analyzing catalytic pockets with topographic steric maps. Organometallics 35, 2286-2293 (2016).

42. Schleis, T., Spaniol, T. P., Okuda, J., Heinemann, J. \& Mulhaupt, R. Ethylene polymerization catalysts based on nickel(II) 1,4-diazadiene complexes: the influence of the 1,4-diazadiene backbone substituents on structure and reactivity. J. Organomet. Chem. 569, 159-167 (1998).

43. Weberski, M. P. et al. Supression of $\beta$-hydride chain transfer in nickel(II)catalyzed ethylene polymerization via weak fluorocarbon ligand-product interactions. Organometallics 31, 3773-3789 (2012).

44. Ittel, S. D., Johnson, L. K. \& Brookhart, M. Late-metal catalysts for ethylene homo- and copolymerization. Chem. Rev. 100, 1169-1203 (2000).

45. Vaidya, T. et al. Secondary alkene insertion and precision chain-walking: a new route to semicrystalline "Polyethylene" from $\alpha$-olefins by combining two rare catalytic events. J. Am. Chem. Soc. 136, 7213-7216 (2014)

46. Johnson, L. et al. Copolymerization of ethylene and acrylates by nickel catalysts. Polym. Mater. Sci. Eng. 86, 319-332 (2002)

47. Chen, Z., Leatherman, M. D., Daugulis, O. \& Brookhart, M. Nickel-catalyzed copolymerization of ethylene and vinyltrialkoxysilanes: catalytic production of cross- linkable polyethylene and elucidation of the chain-growth mechanism. J. Am. Chem. Soc. 139, 16013-16022 (2017).

48. Zhou, S. X. \& Chen, C. L. Synthesis of silicon-functionalized polyolefins by subsequent cobalt-catalyzed dehydrogenative silylation and nickel-catalyzed copolymerization. Sci. Bull. 63, 441-445 (2018).

49. Spekreijse, J., Sanders, J. P. M., Bitter, J. H. \& Scott, E. L. The future of ethenolysis in biobased chemistry. ChemSusChem 10, 470-482 (2017).

50. Na, Y. N., Dai, S. Y. \& Chen, C. L. Direct synthesis of polar-functionalized linear low-density polyethylene (LLDPE) and low-density polyethylene (LDPE). Macromolecules 51, 4040-4048 (2018).

51. Delferro, M. \& Marks, T. J. Multinuclear olefin polymerization catalysts. Chem. Rev. 111, 2450-2485 (2011)

52. $\mathrm{Na}, \mathrm{Y}$. N. et al. Dinuclear $\alpha$-diimine $\mathrm{Ni}(\mathrm{II})$ and $\mathrm{Pd}(\mathrm{II})$ catalyzed ethylene polymerization and copolymerization. ChemCatChem 9, 1062-1066 (2017).

53. Wang, R. K., Sui, X. L., Pang, W. M. \& Chen, C. L. Ethylene polymerization by xanthene bridged dinuclear $\alpha$-diimine $\mathrm{Ni}(\mathrm{II})$ complexes. ChemCatChem $\mathbf{8}$, 434-440 (2016).

54. Severn, J. R., Chadwick, J. C., Duchateau, R. \& Friederichs, N. "Bound but Not Gagged”-immobilizing single-site a-olefin polymerization catalysts. Chem. Rev. 105, 4073-4147 (2005).

55. Stalzer, M. M., Delferro, M. \& Marks, T. J. Supported single-site organometallic catalysts for the synthesis of high-performance polyolefins. Catal. Lett. 145, 3-14 (2015).

56. Baier, M. C., Zuideveld, M. A. \& Mecking, S. Post-metallocenes in the industrial production of polyolefins. Angew. Chem. Int. Ed. 53, 9722-9744 (2014).

57. Preishuber-Pflugl, P. \& Brookhart, M. Highly active supported nickel diimine catalysts for polymerization of ethylene. Macromolecules 35, 6074-6076 (2002).

58. Severn, J. R., Chadwick, J. C. \& Van Axel Castelli, V. $\mathrm{MgCl}_{2}$-based supports for the immobilization and activation of nickel diimine catalysts for polymerization of ethylene. Macromolecules 37, 6258-6259 (2004).

59. Wucher, P., Schwaderer, J. B. \& Mecking, S. Solid-supported singlecomponent $\mathrm{Pd}(\mathrm{II})$ catalysts for polar monomer insertion copolymerization. ACS Catal. 4, 2672-2679 (2014).

60. Tafazolian, H., Culver, D. B. \& Conley, M. P. A well-defined Ni(II) a-diimine catalyst supported on sulfated zirconia for polymerization catalysis. Organometallics 36, 2385-2388 (2017).
61. Huang, C. B. et al. Comparisons between homogeneous and immobilized 1(2,6-dibenzhydryl-4-nitrophenylimino)-2-mesityliminoacenaphthylnickel bromide as a precatalyst in ethylene polymerization. J. Catal. 372, 103-108 (2019).

62. Hlatky, G. G. Heterogeneous single-site catalysts for olefin polymerization. Chem. Rev. 100, 1347-1376 (2000).

63. Coperet, C. et al. Bridging the gap between industrial and well-defined supported catalysts. Angew. Chem. Int. Ed. 57, 6398-6440 (2018).

64. Chen, Z., Mesgar, M., White, P. S., Daugulis, O. \& Brookhart, M. Synthesis of branched ultrahigh-molecular-weight polyethylene using highly active neutral, single-component $\mathrm{Ni}(\mathrm{II})$ catalysts. ACS Catal. 5, 631-636 (2015)

65. Zou, C., Dai, S. Y. \& Chen, C. L. Ethylene polymerization and copolymerization using nickel 2-iminopyridine- $\mathrm{N}$-oxide catalysts: modulation of polymer molecular weights and molecular-weight distributions. Macromolecules 51, 49-56 (2018).

66. Mahmood, Q. et al. Ultra-high molecular weight elastomeric polyethylene using an electronically and sterically enhanced nickel catalyst. Polym. Chem. 8, 6416-6430 (2017)

67. Kenyon, P. \& Mecking, S. Pentafluorosulfanyl substituents in polymerization catalysis. J. Am. Chem. Soc. 139, 13786-13790 (2017).

68. Kenyon, P., Wörner, M. \& Mecking, S. Controlled polymerization in polar solvents to ultrahigh molecular weight polyethylene. J. Am. Chem. Soc. 140, 6685-6689 (2018).

69. Guo, L. H., Dai, S. Y. \& Chen, C. L. Investigations of the ligand electronic effects on a-diimine nickel(II) catalyzed ethylene polymerization. Polymers $\mathbf{8}$, 37 (2016).

70. Schnitte, M., Staiger, A., Casper, L. A. \& Mecking, S. Uniform shape monodisperse single chain nanocrystals by living aqueous catalytic polymerization. Nat. Commun. 10, 2592 (2019).

\section{Acknowledgements}

This work was supported by National Natural Science Foundation of China (NSFC, 21690071 and 21871242), the Fundamental Research Funds for the Central Universities.

\section{Author contributions}

T.L. and C.C.L. conceived the study and planned the research. T.L. and S.B.G. conducted the catalysts synthesis and olefin polymerization experiments. C.C.L. prepared the manuscript.

\section{Competing interests}

The authors declare no competing interests.

\section{Additional information}

Supplementary information is available for this paper at https://doi.org/10.1038/s41467 019-14211-0.

Correspondence and requests for materials should be addressed to C.C.

Peer review information Nature Communications thanks the anonymous reviewers for their contribution to the peer review of this work. Peer reviewer reports are available.

Reprints and permission information is available at http://www.nature.com/reprints

Publisher's note Springer Nature remains neutral with regard to jurisdictional claims in published maps and institutional affiliations.

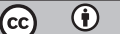

Open Access This article is licensed under a Creative Commons Attribution 4.0 International License, which permits use, sharing adaptation, distribution and reproduction in any medium or format, as long as you give appropriate credit to the original author(s) and the source, provide a link to the Creative Commons license, and indicate if changes were made. The images or other third party material in this article are included in the article's Creative Commons license, unless indicated otherwise in a credit line to the material. If material is not included in the article's Creative Commons license and your intended use is not permitted by statutory regulation or exceeds the permitted use, you will need to obtain permission directly from the copyright holder. To view a copy of this license, visit http://creativecommons.org/ licenses/by/4.0/.

(c) The Author(s) 2020 